\title{
Desilication of ZSM-5 and ZSM-12 Zeolites with Different Crystal Sizes: Effect on Acidity and Mesoporous Initiation
}

\author{
Lidiane Sabino da Silva ${ }^{a}$, Carina Akemi Araki ${ }^{a}$, Silvio Miguel Parmegiani Marcuccia, Victor Luis \\ dos Santos Teixeira da Silva ${ }^{b}$ Pedro Augusto Arroyo ${ }^{a}$ \\ aPrograma de Pós-Graduação em Engenharia Química (PEQ), Universidade Estadual de Maringá \\ (UEM), 87020-900, Maringá, PR, Brasil \\ ${ }^{b}$ Programa de Engenharia Química (COPPE), Universidade Federal do Rio de Janeiro (UFRJ), 21941 - \\ 914, Rio de Janeiro, RJ, Brasil
}

Received: December 08, 2018; Accepted: January 17, 2019

\begin{abstract}
In the present work, the desilication of the H-ZSM-5 and H-ZSM-12 zeolites with Si/AL ratios of 28 and 56 and crystal sizes of around 200 and $600 \mathrm{~nm}$, respectively, was performed. Through electron transmission microscopy analysis, it was possible to verify the influence of aluminium gradients on smaller crystals in addition to the exact moment at which the formation of mesoporous is initiated inside the zeolitic framework. Moreover, the crystal size exerts a significant influence on the total amount of acid sites remaining after alkaline treatment, as verified by means of temperature-programmed desorption of ammonia. This is because the presence of larger crystals during desilication may increase the likelihood of reinsertion of aluminium atoms in the zeolite framework and, consequently, maintain the same total amount of acid sites in the zeolite as before alkaline treatment. Meanwhile, aluminium atoms tend to be removed from smaller crystals, thereby decreasing the total amount of acid sites.
\end{abstract}

Keywords: Desilication, pentasil zeolites, sodium hydroxide, intracrystalline mesoporosity, strong and weak acid sites.

\section{Introduction}

In catalytic reactions with bulky molecules, the unique presence of micropores in zeolites can limit catalytic performance by restricting molecular transport within its crystals. Possible solutions to this problem would be to decrease the zeolite crystal size or to develop materials with larger pores.

The decrease in the crystal size reduces the path for diffusion of the reagents. However, zeolitic nanocrystals tend to aggregate and often present different properties when compared with traditional materials, such as lower stability and loss of crystallinity ${ }^{1}$.

On the other hand, the development of materials with additional porosity combines the advantages of the conventional microporous zeolites, which possess acidic catalytic functions and shape-selective features and are stable at high temperatures because of the crystalline structures, and the mesoporous materials with efficient mass transport ${ }^{2}$.

Post-synthesis treatments based on the preferential removal of aluminium (dealumination) or silicon (desilication) from the zeolitic structure may leave vacancies with sizes of the order of magnitude of mesopores and/or macropores, depending on the intensity of the treatment.

Dealumination is performed by steam treatment at high temperatures or by leaching with acidic solutions. The treatment has the disadvantage of significantly altering the acidic properties of the catalyst due to the extraction of aluminium

*e-mail: lidiane_eq@hotmail.com from the zeolite framework. In this case, the facilitated transport acquired by the introduction of mesoporosity is partially cancelled out by the reduced density of acid sites ${ }^{3}$.

Still, desilication can be carried out through leaching with alkaline solutions. The alkaline treatment preferably extracts silicon atoms from the zeolite framework. It is a promising methodology for obtaining mesoporosity in zeolites, especially those with high silica content, since under optimal treatment conditions a considerable amount of mesopores are obtained without destroying the microporous structure of the zeolite; at the same time, the acidic properties of the material are preserved, since the amount of Al is not significantly altered, and in addition, the external area of the catalyst is significantly increased ${ }^{3}$.

The $\mathrm{Si} / \mathrm{Al}$ ratio of zeolitic structures is a relevant parameter in obtaining additional porosity by means of desilication. Groen et al. ${ }^{4,5}$ show that high aluminium concentrations $(\mathrm{Si} / \mathrm{Al}<20)$ prevent the removal of silicon from zeolites, thus hindering the formation of pores. However, structures with high silicon contents $(\mathrm{Si} / \mathrm{Al}>50)$ show excessive and unselective silicon dissolution, leading to the creation of relatively large pores. So, a framework $\mathrm{Si} / \mathrm{Al}$ ratio of 25 50 enables a controlled mesoporosity development with preserved crystalline and acidic properties.

This behaviour occurs because of the kinetics of silicon extraction. Due to the negative charges of $\mathrm{AlO}_{4}$ - tetrahedra, the hydrolysis of $\mathrm{Si}-\mathrm{O}-\mathrm{Al}$ bonds is hindered compared to the relatively easy cleavage of the $\mathrm{Si}-\mathrm{O}-\mathrm{Si}$ linkage in the absence of neighbouring aluminium tetrahedra ${ }^{4,6}$. Thus, 
materials with a high amount of aluminium are relatively inert to silicon extraction and require more severe conditions during desilication, such as higher concentrations of basic solution and/or longer treatment intervals. On the other hand, silicon is easily extracted from materials with a low amount of aluminium and can often cause excess mesoporosity or even the collapse of the structure depending on the desilication conditions.

Despite the broad literature on the subject, the articles do not report the effects of desilication on crystals of different sizes ${ }^{7-16}$. In this context, the main goal of this study was to characterize the ZSM-5 and ZSM-12 zeolites with different crystals sizes and $\mathrm{Si} / \mathrm{Al}$ ratio ideal for the generation of intracrystalline porosity by silicon removal. Besides, it were evaluated the effect of the crystal size on mesopore initiation and the behaviour of the acid sites before and after the desilication using sodium hydroxide under varied conditions.

\section{Experimental}

\subsection{Zeolites}

\subsubsection{ZSM-5}

The parent ZSM-5 ( $\mathrm{Si} / \mathrm{Al}=28)$ was kindly provided by Cenpes/Petrobras. In order to obtain the protonic form of the zeolite, the solid was exchanged twice with an aqueous $1 \mathrm{M}$ $\mathrm{NH}_{4} \mathrm{Cl}$ solution at room temperature for $24 \mathrm{~h}$. After the ion exchange, the zeolite was filtered and washed with enough deionized water at $80{ }^{\circ} \mathrm{C}$ and then, after drying in an oven at $100{ }^{\circ} \mathrm{C}$ for $12 \mathrm{~h}, \mathrm{NH}_{4}$-zeolite was calcined in the static air at $550{ }^{\circ} \mathrm{C}$ for $3 \mathrm{~h}$ to obtain H-ZSM-5.

\subsubsection{ZSM-12}

The parent ZSM-12 was synthesized according to the procedure described by Gopal et al. ${ }^{17}$. For the synthesis, tetraethylammonium hydroxide (TEAOH) was used as the template, colloidal silica (Ludox) as the silica source, and sodium aluminium oxide as the aluminium source. The preparation of the reaction mixture occurred through the dilution of the TEAOH and sodium aluminium in water followed by subsequent addition of the silica source, under agitation, until the solution became uniform. The resulting composition of the mixture was:

$$
70 \mathrm{SiO}_{2}: \mathrm{Al}_{2} \mathrm{O}_{3}: 0.88 \mathrm{Na}_{2} \mathrm{O}: 11.1 \mathrm{TEAOH}: 910 \mathrm{H}_{2} \mathrm{O}
$$

The solution was then transferred to a Teflon-lined stainless steel autoclave and crystallization was carried out at $160^{\circ} \mathrm{C}$ under autogenous pressure in static conditions for 5.5 days. The product was recovered by filtration, washed with deionized water, and dried at $100{ }^{\circ} \mathrm{C}$ for $12 \mathrm{~h}$. The organic template was removed by calcination in the static air at $520^{\circ} \mathrm{C}$ for $4 \mathrm{~h}$. In order to obtain the protonic form of the zeolite, the solid was exchanged twice with an aqueous $1 \mathrm{~mol} \mathrm{~L}^{-1} \mathrm{NH}_{4} \mathrm{Cl}$ solution at room temperature for $24 \mathrm{~h}$. After the ion exchange, the zeolite was filtered and washed with enough deionized water at $80^{\circ} \mathrm{C}$ and then, after drying in an oven at $100{ }^{\circ} \mathrm{C}$ for $12 \mathrm{~h}, \mathrm{NH}_{4}$-zeolite was calcined in conventional furnace at $550^{\circ} \mathrm{C}$ for $3 \mathrm{~h}$ to obtain H-ZSM- 12 .

\subsection{Desilication}

Desilication was performed according to the procedure proposed by Sartipi et al. ${ }^{18}$ with the aim of inserting additional porosity in the zeolites. The treatment consisted of stirring a certain amount of zeolite in a solution of sodium hydroxide $\left(\mathrm{V}_{\text {alkaline solution }} / \mathrm{m}_{\text {zeolite }}=30 \mathrm{~cm}^{3} \mathrm{~g}^{-1}\right)$ at a specific temperature during a given interval. The system was then cooled in an ice bath and thereafter vacuum filtered or centrifuged in several cycles until a neutral $\mathrm{pH}$ was reached and the zeolite powder was separated from the solution. In order to remove sodium traces, the zeolites were ion-exchanged with $0.1 \mathrm{~mol}$ $\mathrm{L}^{-1} \mathrm{NH}_{4} \mathrm{Cl}$ at $60^{\circ} \mathrm{C}$ for $1 \mathrm{~h}$. The recovered material was kept in an oven at $100{ }^{\circ} \mathrm{C}$ for $12 \mathrm{~h}$ and then calcined in the static air at $550{ }^{\circ} \mathrm{C}$ for $5 \mathrm{~h}$.

The conditions used in desilication are shown in Table 1.

\subsection{Characterization}

\subsubsection{X-Ray Diffraction}

The X-ray diffraction (XRD) patterns were collected with a Shimadzu XRD6000 X-ray diffractometer using Ni-filtered $\mathrm{Cu}-\mathrm{K} \alpha(40 \mathrm{kV}$ and $30 \mathrm{~mA})$ radiation with a diffraction angle ${ }^{\circ}(2 \Theta)$ ranging from 5 to 60 . All crystalline phases were determined by comparing the results with the diffraction patterns of the standards of the JCPDS database and articles available in the literature. The degree of crystallinity of the desilicated samples was determined through X-ray diffraction by the measurement of the areas of characteristic peaks at ${ }^{\circ} 2 \Theta=\sim 23.08,23.88$ and $24.36^{\circ}$ for H-ZSM-5 and $^{\circ} 2 \Theta=\sim 20.88$ and $23.20^{\circ}$ for H-ZSM-12 and comparison with the areas of the same peaks of a standard sample considered as $100 \%$ crystalline.

Table 1. Conditions used in desilication.

\begin{tabular}{lccc}
\hline Zeólite & $\begin{array}{c}\text { NaOH } \\
\left(\mathbf{m o l ~ L}^{-1}\right)\end{array}$ & $\begin{array}{c}\text { Temperature } \\
\left({ }^{\circ} \mathbf{C}\right)\end{array}$ & $\begin{array}{c}\text { Time } \\
(\mathbf{m i n})\end{array}$ \\
\hline $\begin{array}{l}\text { H-ZSM-5 } \\
\text { (D1) }\end{array}$ & 0.1 & 50 & 30 \\
$\begin{array}{l}\text { H-ZSM-5 } \\
\text { (D2) }\end{array}$ & 0.2 & 70 & 30 \\
$\begin{array}{l}\text { H-ZSM-5 } \\
\text { (D3) }\end{array}$ & 0.2 & 85 & \\
$\begin{array}{l}\text { H-ZSM-12 } \\
\text { (D1) }\end{array}$ & 0.1 & 50 & 30 \\
$\begin{array}{l}\text { H-ZSM-12 } \\
\text { (D2) }\end{array}$ & 0.2 & 70 & 30 \\
\hline
\end{tabular}




\subsubsection{Atomic Absorption Espectrometry}

The Si/Al ratio of the materials in the calcined form was determined by Atomic Absorption Espectrometry (AAE) in Varian GTA 120 equipment. Prior to analysis, the samples were digested as follows: approximately $0.2 \mathrm{~g}$ of the sample was mixed with $0.5 \mathrm{~mL}$ of aqua regia $\left(\mathrm{HNO}_{3}: \mathrm{HCl}\right.$ at $\left.1: 3\right)$ and $3.0 \mathrm{~mL}$ of hydrofluoric acid; then the solution was heated until became clear. The solutions were cooled and then $10 \mathrm{~mL}$ of water, $5.0 \mathrm{~mL}$ of $4 \% \mathrm{H}_{3} \mathrm{BO}_{3}$, and $1.0 \mathrm{~mL}$ of hydrochloric acid were added. After further heating, the solutions were cooled, transferred, and diluted in $100 \mathrm{~mL}$ volumetric flasks. The solutions were then immediately stored in plastic bags prior to analysis to avoid the risk of contamination.

\subsection{3. $N_{2}$ Physisorption}

The $\mathrm{N}_{2}$ adsorption-desorption isotherms were measured by Micromeritics ASAP 2020 equipment. The textural properties were determined by means of the adsorption and desorption of nitrogen at $-196{ }^{\circ} \mathrm{C}$. Before measurement, the samples (ca. $100 \mathrm{mg}$ ) were treated in vacuum at $200{ }^{\circ} \mathrm{C}$ for $12 \mathrm{~h}$ in order to ensure complete drying of the material. The BET surface area ${ }^{19}$ was derived from the adsorption isotherm in the adapted relative pressure range of $\mathrm{p} / \mathrm{p}_{0}=0.01-0.1$. The mesopore size distribution and mesopore diameter of the zeolites were determined by the BJH method ${ }^{20}$ following the adsorption branch of the isotherm. The total pore volume was obtained from the amount of nitrogen adsorbed at the relative pressure of about $\mathrm{p} / \mathrm{p}_{0}=0.99$. The micropore volume and micropore area were estimated by the t-plot method ${ }^{21}$.

\subsubsection{Transmission Electron Microscopy}

Transmission Electron Microscopy (TEM) was carried out using a JEM 1400 microscope. The analysis was carried out in order to verify the size of the crystals and insertion of additional porosity in the zeolites after desilication. The samples were prepared using a small amount of zeolite suspension in isopropyl alcohol. After the preparation, the suspension was kept for about an hour in an ultrasound bath with the aim of achieving maximum dispersion of zeolites in the medium. Then, a drop of solution was placed carefully on a copper grid $(0.3 \mathrm{~cm}$ in diameter and 200 mesh from Ted Pella) covered with a carbon film. The grids prepared for analysis were dried overnight at room temperature and subsequently inserted into the microscope to obtain the images.

\subsubsection{Temperature-Programmed Desorption of Ammonia}

The number and strength of the acid sites on the surface of the zeolites before and after desilication were studied by temperature-programmed desorption of ammonia using a Quantachrome ChemBet 3000 instrument. The sample (100 $\mathrm{mg}$ ) was pretreated at 300 and $500^{\circ} \mathrm{C}$ in $\mathrm{N}_{2}\left(90 \mathrm{~mL} \mathrm{~min}^{-1}\right)$ for $1 \mathrm{~h}$, using a heating rate of $10^{\circ} \mathrm{C} \mathrm{min}^{-1}$, after which $\mathrm{NH}_{3}-\mathrm{He}$ mixture $\left(5 \mathrm{vol} \% \mathrm{NH}_{3}\right)$ was adsorbed at $100{ }^{\circ} \mathrm{C}$ for $30 \mathrm{~min}$. Then a flow rate of $\mathrm{N}_{2}\left(90 \mathrm{~mL} \mathrm{~min}{ }^{-1}\right)$ was passed through the reactor for $2 \mathrm{~h}$ to remove weakly adsorbed $\mathrm{NH}_{3}$ from the zeolite. Thereafter, desorption of $\mathrm{NH}_{3}$ was monitored in the temperature range of $100-700^{\circ} \mathrm{C}$ using a heating rate of $10^{\circ} \mathrm{C} \mathrm{min}^{-1}$ under flow rate of $\mathrm{N}_{2}\left(90 \mathrm{mLmin}^{-1}\right)$. The amount of acid sites was calculated from the desorption profile of the $\mathrm{NH}_{3}$ molecules, considering a stoichiometry of $1: 1\left(\mathrm{NH}_{3}: \mathrm{Al}\right)$.

\section{Results and Discussion}

The synthesized and desilicated zeolites were characterized by XRD analysis as shown in Figure 1. This technique is the most appropriate for the identification of crystalline phases, because in these types of structures the atoms are ordered in crystalline planes separated by distances of the same order of magnitude as the wavelengths of the X-rays. Comparing the zeolite diffractogram of H-ZSM-5 shown in Figure 1a with other standards available in the literature ${ }^{22,23}$, it is possible to state that the material corresponds to an H-ZSM-5 zeolite with high crystallinity and without the presence of undesirable phases. The same conclusion can be reached on observing the zeolite diffractograms of H-ZSM-12, shown in Figure $1 b^{17,24-27}$.

The variation of the zeolite crystallinity and $\mathrm{Si} / \mathrm{Al}$ ratios before and after desilication is presented in Table 2 .

The decrease in peak intensity after desilication is visible only in the H-ZSM-12 (D2) (Figure 1b). However, in Table 2 is shown the decrease in crystallinity for all desilicated zeolites. The more severe the treatment conditions, the lower the intensities of the characteristic peaks in relation to the standard sample.

The decrease in the crystallinity of the zeolites after desilication occurs due to the removal of silicon from the framework, which leads to a disordering of the structural arrangement or a partial collapse of the structure in the desilicated regions ${ }^{23}$.

The $\mathrm{Si} / \mathrm{Al}$ ratio interval of the standard zeolites was very close to the optimal one (between 25 and 50) considered for desilication treatment ${ }^{5}$. After the treatment, the $\mathrm{Si} / \mathrm{Al}$ ratio decreased in all the structures due to selective silicon extraction, as expected.

In addition, Wei and Smirniotis ${ }^{6}$ showed that $\mathrm{Si} /$ $\mathrm{Al}$ ratios between 31 and 58 in ZSM-12 are ideal for the development of uniform intracrystalline mesoporosity by means of desilication and simultaneous preservation of the acid sites, in agreement with the results obtained in the present study for this zeolite.

The $\mathrm{N}_{2}$ adsorption/desorption isotherms of the standard zeolites and after desilication are shown in Figure 2. All the zeolites presented type I isotherms, characteristic of microporous materials. In this case, adsorption occurs at very low relative pressures due to the interaction of the pore walls with the adsorbate. However, the presence of 

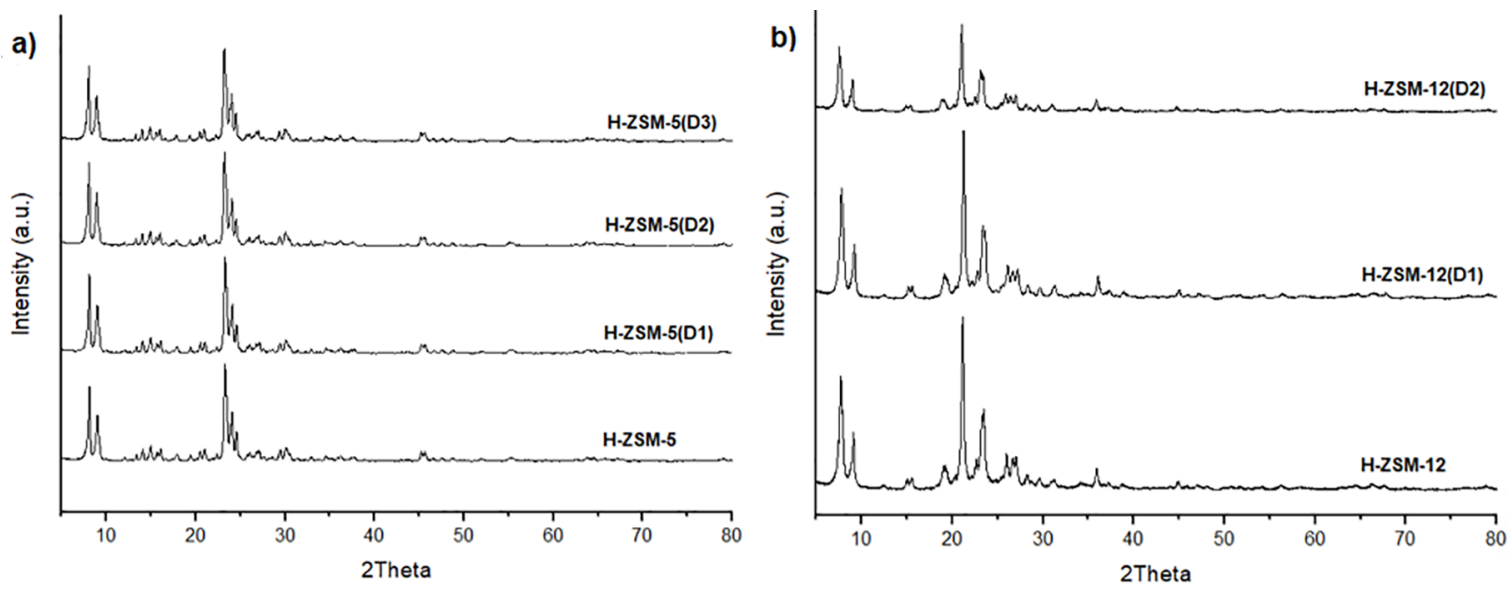

Figure 1. X-ray diffraction patterns before and after desilication. a) H-ZSM-5 and b) H-ZSM-12.

Table 2. Crystallinity and $\mathrm{Si} / \mathrm{Al}$ ratios of the zeolites before and after desilication

\begin{tabular}{lcc}
\hline Zeolite & Crystallinity (\%) & Si/Al \\
\hline H-ZSM-5 & 100 & 28 \\
H-ZSM-5 (D1) & 99.4 & 25 \\
H-ZSM-5 (D2) & 89.0 & 23 \\
H-ZSM-5 (D3) & 84.0 & 20 \\
H-ZSM-12 & 100 & 56 \\
H-ZSM-12 (D1) & 97.2 & 46 \\
H-ZSM-12 (D2) & 50.6 & 37 \\
\hline
\end{tabular}

hysteresis, mainly in desilicated zeolites, suggests the presence of mesoporosity ${ }^{28,29}$.

This behaviour occurs because the desorption of adsorbate after saturation is complete is the opposite process to adsorption. However, desorption in mesopores generally occurs at relative pressures lower than those at which capillary condensation occurs, thereby leading to hysteresis.

Thus, the isotherms of the H-ZSM-5 zeolites presented H4 type hysteresis and the H-ZSM-12 zeolites presented H3 type hysteresis, which characterize solids formed by aggregates or particle clusters forming slit pores of uniform (H4 type) or non-uniform (H3 type) size and shape.

The presence of additional porosity due to the desilication process could be confirmed by the distribution of mesopore size presented in Figure 3. This suggests that the insertion of additional porosity in the zeolites occurred, mainly in the mesoporous range ( 2 to $50 \mathrm{~nm}$ ). The more severe the treatment, the greater the insertion of porosity. However, most of the material still has microporous features, as discussed earlier.

The texture parameters of the zeolites studied are shown in Table 3. In general, there was an increase in the surface area and volume of mesopores after desilication, but the volume of micropores was little affected. Therefore, the total pore volume of the zeolites was increased as a consequence of the treatment and there was greater accessibility to the internal zeolitic space.
Despite the high degree of mesoporosity after the desilication treatment, the microporosity of the H-ZSM-5 and H-ZSM-12 zeolites was maintained. This justifies the occurrence of the characteristic isotherms of microporous materials in both the untreated and alkaline-treated zeolites.

Moreover, the higher the concentration of the alkaline solution, the greater the insertion of mesoporosity in the structures; also, the higher the treatment temperature, the greater the presence of mesopores. In the latter case, the higher temperature enables the extraction of a fraction of silicon atoms that would be stabilized by the neighbouring aluminium atoms at lower temperatures ${ }^{4}$.

TEM images of the standard and desilicated H-ZSM-5 are shown in Figure 4, in which is possible to visualize the crystals presenting hexagonal plate shape and dimensions of approximately $100 \times 200 \mathrm{~nm}$. Moreover, it is evident that the more severe the treatment, the greater the insertion of porosity inside the zeolitic framework. This behaviour probably occurred due to the excess of aluminium on the surface and protection of the neighbouring silicon atoms by the negatively charged $\mathrm{AlO}_{4}^{-}$against the attack of the $\mathrm{OH}^{-}$groups, thus leading to the formation of intracrystalline pores ${ }^{30,31}$.

It has already been shown that in larger crystals (above $1 \mu \mathrm{m})$ the desilication started inside the crystal due to the higher occurrence of aluminium near the external surface of 

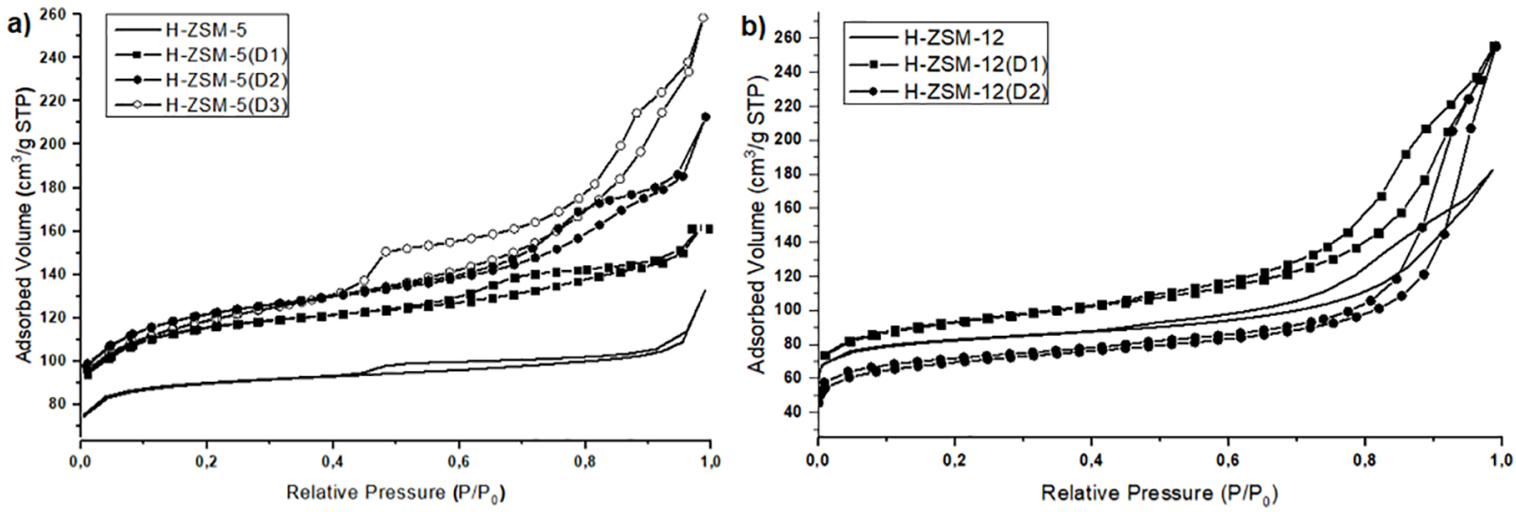

Figure 2. N2 adsorption and desorption isotherms.a) H-ZSM-5 and b) H-ZSM-12.
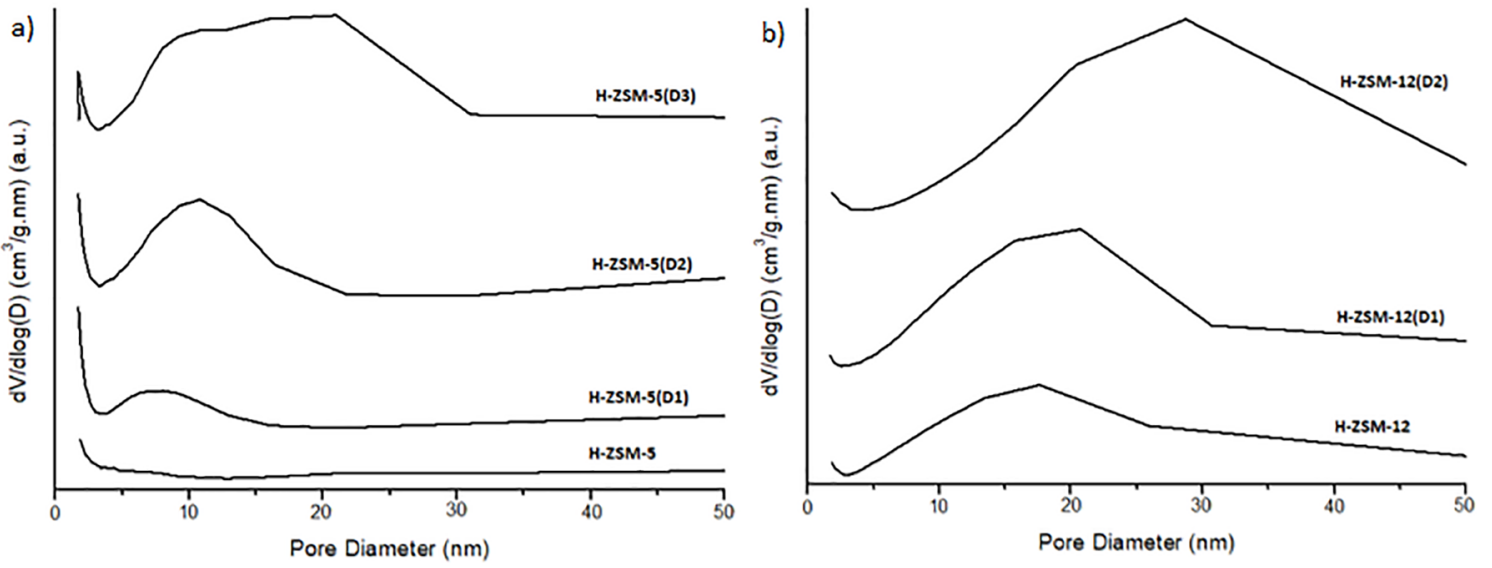

Figure 3. Mesopore size distribution before and after desilication. a) H-ZSM-5 and b) H-ZSM-12.

Table 3. Textural parameters of the standard and desilicated zeolites.

\begin{tabular}{lcccccccc}
\hline Zeolites & $\mathbf{A}_{\text {esp }}{ }^{\mathbf{a}}\left(\mathbf{m}^{\mathbf{2}} \mathbf{g}^{-1}\right)$ & $\mathbf{A}_{\text {micro }}{ }^{\mathbf{b}}\left(\mathbf{m}^{\mathbf{2}} \mathbf{g}^{-1}\right)$ & $\mathbf{A}_{\text {meso }}{ }^{\mathbf{c}}\left(\mathbf{m}^{\mathbf{2}} \mathbf{g}^{-1}\right)$ & $\mathbf{V}_{\text {total }}{ }^{\mathbf{d}}\left(\mathbf{c m}^{\mathbf{3}} \mathbf{g}^{-1}\right)$ & $\mathbf{V}_{\text {micro }}{ }^{\mathbf{e}}\left(\mathbf{c m}^{\mathbf{3}} \mathbf{g}^{-1}\right)$ & $\mathbf{V}_{\text {meso }}^{\mathbf{f}}\left(\mathbf{c m}^{\mathbf{3}} \mathbf{g}^{-1}\right)$ & $\mathbf{D}_{\text {meso }}{ }^{\mathbf{g}}(\mathbf{\AA})$ \\
\hline H-ZSM-5 & 344 & 284 & 37,2 & 0.21 & 0.11 & 0.08 & - \\
H-ZSM-5 (D1) & 439 & 332 & 88.1 & 0.25 & 0.13 & 0.11 & 48.6 \\
H-ZSM-5 (D2) & 453 & 321 & 114 & 0.33 & 0.13 & 0.19 & 66.1 \\
H-ZSM-5 (D3) & 437 & 278 & 142 & 0.40 & 0.11 & 0.27 & 77.3 \\
H-ZSM-12 & 314 & 239 & 64.9 & 0.28 & 0.09 & 0.18 & - \\
H-ZSM-12 (D1) & 344 & 220 & 118 & 0.40 & 0.09 & 0.30 & 102 \\
H-ZSM-12 (D2) & 263 & 169 & 78.0 & 0.40 & 0.07 & 0.32 & 164 \\
\hline
\end{tabular}

aspecific area determined by the BET method.

${ }^{b}$ Micropore area determined by the t-plot method.

${ }^{\mathrm{c}}$ Mesopore area determined by the BJH method.

dTotal pore volume determined at relative pressures of around 0.99 .

${ }^{\mathrm{e}}$ Micropore volume determined by the t-plot method.

${ }^{\mathrm{f}}$ Mesopore volume determined by the BJH method.

gMesopore diameter determined by the BJH method.

the zeolite ${ }^{30,32}$. However, Figures $4 a$ and $4 b$ show the exact moment when the formation of the mesopores is initiated, demonstrating that even in smaller crystals the formation of mesoporosity also begins inside the structure. This highlights the influence of the aluminium gradients even in smaller crystals and complements the study by Groen et al. ${ }^{31}$, which showed an influence of the gradient only after treatment.

In general, the generation of pores in the zeolites through the desilication resulted in short intracrystalline diffusion pathways, with larger pores connected to the outer surface of 


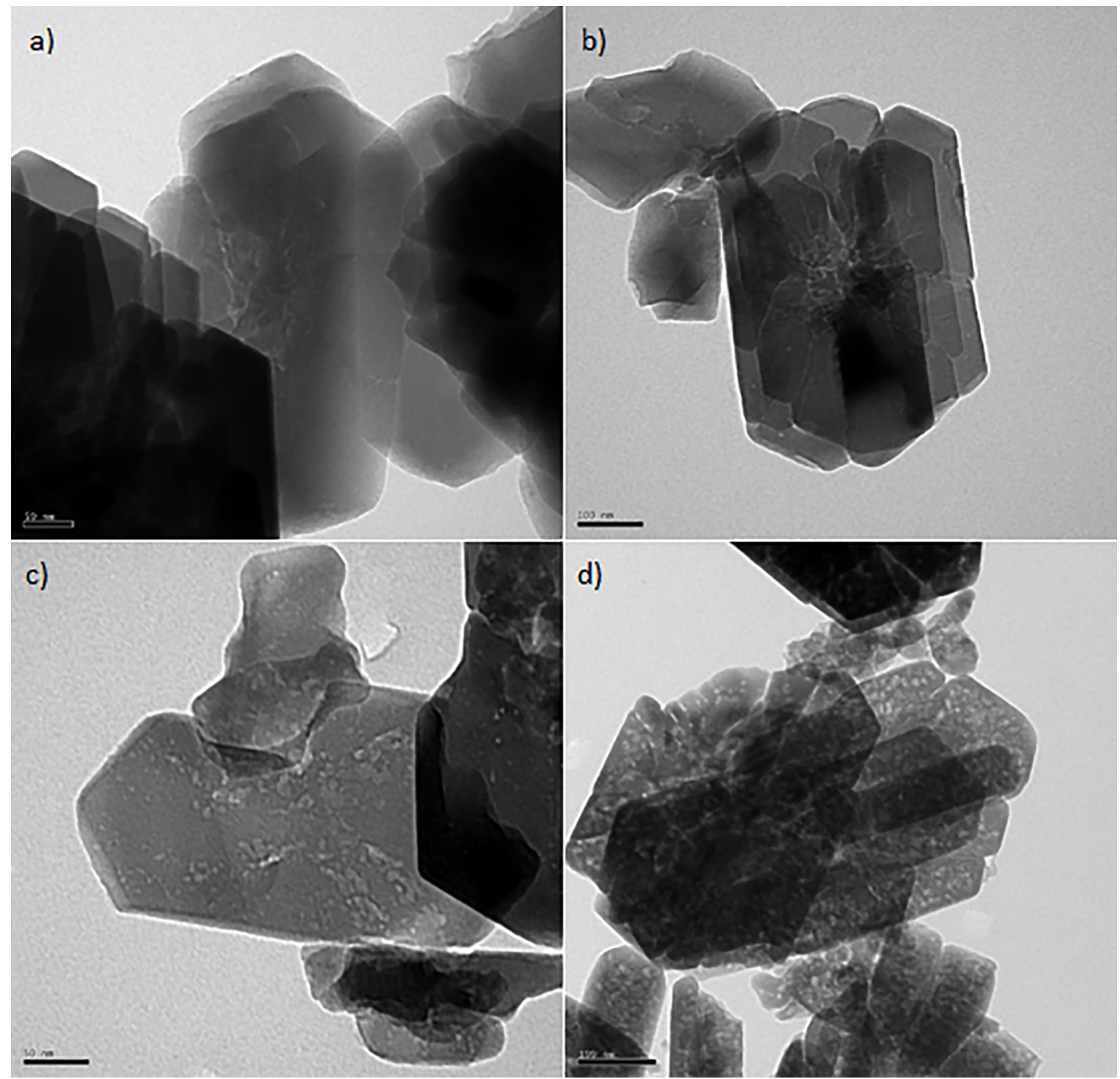

Figure 4. TEM images of the H-ZSM-5 zeolites: a) and b) H-ZSM-5(D1); c) H-ZSM-5(D2); and d)H-ZSM-5(D3).

the crystals (Figures 4c and 4d) which were distributed evenly in the structure. This behaviour favoured the maintenance of the microporous properties and characteristic structure of H-ZSM-5, as observed in the XRD and adsorption/ desorption of $\mathrm{N}_{2}$.

TEM images of the standard and desilicated H-ZSM-12 are shown in Figure 5. Due to the cubic form of the H-ZSM-12 crystals, with edge lengths approximately equal to $600 \mathrm{~nm}$, it was not possible to find less dense regions in which the pores that formed after the desilication could be viewed. However, the insertion of pores was confirmed by means of the $\mathrm{N}_{2}$ physisorption analysis, as discussed earlier.

In addition, Groen et al. ${ }^{33}$ have already shown that desilication is only inefficient for crystals larger than 3 $\mu \mathrm{m}$, due to limitations in mass transfer during the process or the occurrence of aluminium gradients, resulting in more resistant particles.

Through the analysis of temperature-programmed desorption of ammonia, the total amount of acid sites and the distributions of weak and strong acid sites of the zeolites before and after the desilication were obtained. The calculated values are shown in Table 4.

In Table 4 is shown the decrease in the relative amount of strong acid sites accompanied by the increase in the relative amount of weak acid sites as the samples are desilicated under more severe conditions. The decrease of the strong acid sites indicates that the desilication also causes the removal of tetrahedrally coordinated structural aluminium ${ }^{34}$, while the increase in weak acid sites is due to the transformation of some framework aluminium into extraframework aluminium 

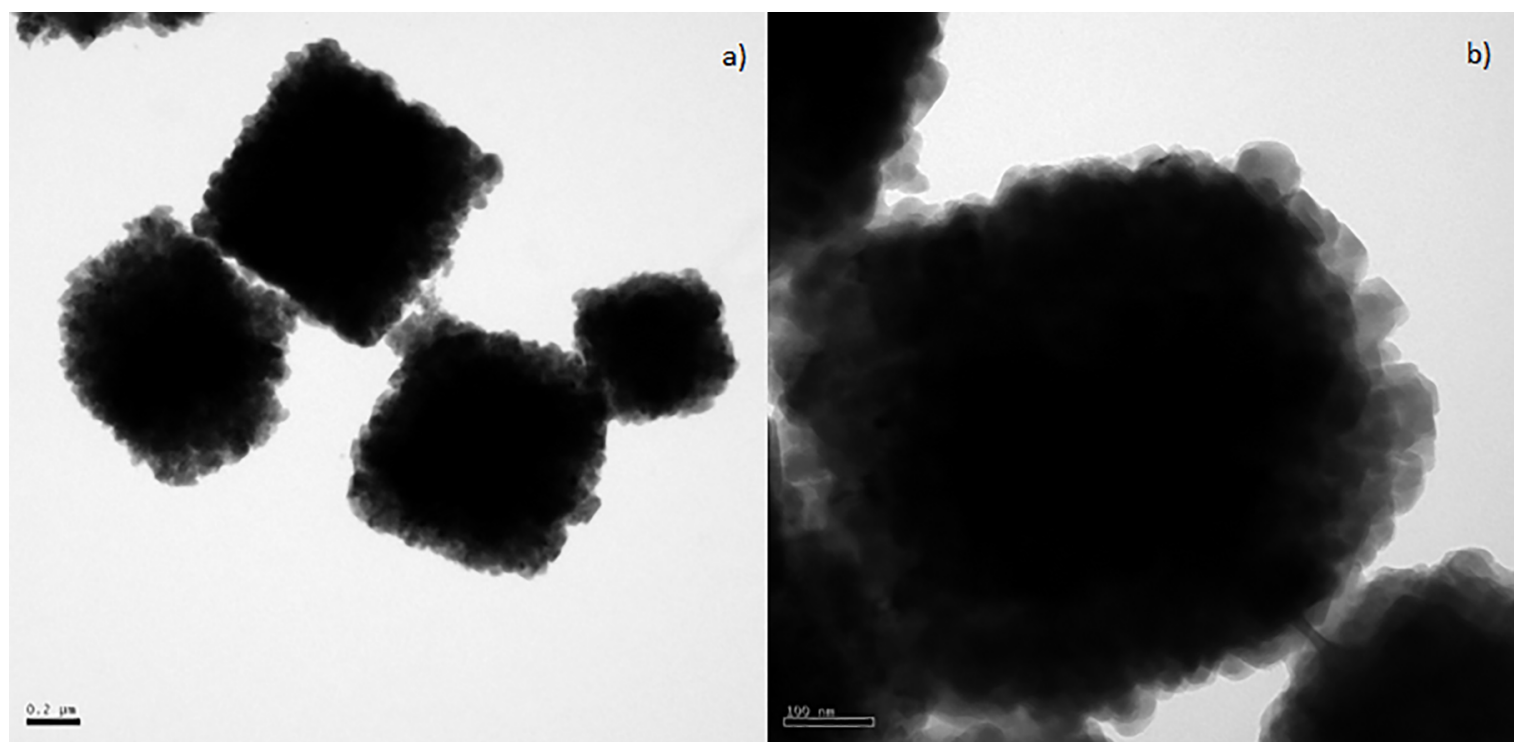

Figure 5. TEM images of the H-ZSM-12 zeolites.

Table 4. Total acidity and quantity of weak and strong acid sites.

\begin{tabular}{|c|c|c|c|c|c|}
\hline \multirow{2}{*}{ Zeolite } & \multicolumn{2}{|c|}{ Maximum temperature $\left({ }^{\circ} \mathrm{C}\right)$} & \multirow{2}{*}{$\begin{array}{l}\text { Weak acid sites } \\
\left(\mathrm{mmol} \mathrm{g}_{\text {zeolite }}{ }^{-1}\right)\end{array}$} & \multirow{2}{*}{$\begin{array}{l}\text { Strong acid sites } \\
\left(\mathbf{m m o l} \mathrm{g}_{\text {zeolite }}^{-1}\right)\end{array}$} & \multirow{2}{*}{$\begin{array}{c}\text { Total number of } \\
\text { acid sites (mmol } \\
\left.\mathrm{g}_{\text {zeolite }}{ }^{-1}\right) \\
\end{array}$} \\
\hline & weak acid sites & strong acid sites & & & \\
\hline H-ZSM-5 & 273 & 473 & $0.216(53 \%)$ & $0.192(47 \%)$ & 0.407 \\
\hline H-ZSM-5 (D1) & 269 & 453 & $0.176(53 \%)$ & $0.161(47 \%)$ & 0.337 \\
\hline H-ZSM-5 (D2) & 238 & 433 & $0.202(59 \%)$ & $0.141(41 \%)$ & 0.343 \\
\hline H-ZSM-5 (D3) & 239 & 425 & $0.190(68 \%)$ & $0.092(32 \%)$ & 0.282 \\
\hline H-ZSM-12 & 299 & 499 & $0.050(40 \%)$ & $0.076(60 \%)$ & 0.127 \\
\hline H-ZSM-12 (D1) & 245 & 429 & $0.065(50 \%)$ & $0.064(50 \%)$ & 0.129 \\
\hline H-ZSM-12 (D2) & 232 & 417 & $0.070(55 \%)$ & $0.058(45 \%)$ & 0.128 \\
\hline
\end{tabular}

during the removal of the silanol groups for the generation of mesopores ${ }^{18}$.

In addition, the total acidity of the H-ZSM- 5 decreased gradually as the zeolites were desilicated in harsher conditions, which is a direct indication of the concomitant removal of aluminium from the zeolitic framework ${ }^{35}$. However, this behaviour did not occur with H-ZSM-12, which kept the total acid sites practically constant even after the alkaline treatments. This suggests the transformation of the strong acid sites into weak acid sites in H-ZSM-12, whereas in the H-ZSM-5, part of the aluminium was indeed removed from the zeolitic framework.

The results suggest the probable removal of aluminium atoms from the zeolitic framework after desilication when the crystals of the zeolite have a reduced size, as in H-ZSM-5, since the amount of acid sites decreases after treatment. Meanwhile in larger crystals, as in ZSM-12, most strong acid sites become weak acid sites due to the reinsertion of aluminium into the structure, since in this case the total amount of acid sites remains constant after treatment. In the latter case, the aluminium atoms must go through longer diffusion paths to be effectively removed from the crystal, providing a greater probability of occurrence of realumination during these paths.

\section{Conclusions}

The present results confirm that even in crystals of reduced size, the occurrence of aluminium gradients is so significant that it leads to the start of generation of mesopores in the interior of the crystal. Until now, this behaviour has been evidently proved only in crystals of larger size (above $1 \mu \mathrm{m})$. Moreover, crystal size exerts a significant influence on the total amount of acid sites remaining after silicon removal. This is because in larger crystals (approximately $600 \mathrm{~nm}$ ) there is a greater probability that the aluminium atoms removed during the desilication are reinserted into the zeolitic framework, since the atoms must pass through longer diffusion paths to be effectively removed from the structure. Thus, in larger crystals, there is a greater tendency for the total amount of acidic sites to remain constant after desilication. 


\section{Acknowledgements}

The authors are grateful to Coordination for the Improvement of Higher Education Personnel (CAPES/ Brazil) and National Council for Scientific and Technological Development (CNPq/Brazil) for financial support and to Central Complex for Research Support (COMCAP/UEM) for TEM analyses.

\section{References}

1. Tao Y, Kanoh H, Abrams L, Kaneko K. Mesopore-Modified Zeolites: Preparation, Characterization, and Applications. Chemical Reviews. 2006;106(3):896-910.

2. Cheng K, Kang J, Huang S, You Z, Zhang Q, Ding J, et al. Mesoporous Beta Zeolite-Supported Ruthenium Nanoparticles for Selective Conversion of Synthesis Gas to C5-C11 Isoparaffins. ACS Catalysis. 2012;2(3):441-449.

3. Groen JC, Sano T, Moulijn JA, Pérez-Ramírez J. Alkalinemediated mesoporous mordenite zeolites for acid-catalyzed conversions. Journal of Catalysis. 2007;251(1):21-27.

4. Groen JC, Peffer LAA, Moulijn JA, Pérez-Ramírez J. Mechanism of Hierarchical Porosity Development in MFI Zeolites by Desilication: The Role of Aluminium as a Pore-Directing Agent. Chemistry A European Journal. 2005;11(17):4983-4994.

5. Groen JC, Jansen JC, Moulijn JA, Pérez-Ramírez J. Optimal Aluminum-Assisted Mesoporosity Development in MFI Zeolites by Desilication. Journal of Physical Chemistry B. 2004;108(35):13062-13065.

6. Wei X, Smirniotis PG. Development and characterization of mesoporosity in ZSM-12 by desilication. Microporous and Mesoporous Materials. 2006;97(1-3):97-106.

7. Sousa LV, Silva AOS, Silva BJB, Quintela PHL, Barbosa CBM, Fréty R, et al. Preparation of zeolite $\mathrm{P}$ by desilication and recrystallization of zeolites ZSM-22 and ZSM-35. Materials Letters. 2018;217:259-262.

8. Gackowski M, Tarach K, Kuterasinski L, Podobinski J, Jarczewski S, Kustrowski P, et al. Hierarchical zeolites Y obtained by desilication: Porosity, acidity and catalytic properties. Microporous and Mesoporous Materials. 2018;263:282-288.

9. Akyalcin S, Akyalcin L, Bjørgen M. Optimization of desilication parameters of low-silica ZSM-12 by Taguchi method. Microporous and Mesoporous Materials. 2019;273:256-264.

10. Wang Y, Liu K, He T, Wu J, Fang Y. Zeolite with trimodal porosity by desilication of zeolite nanocrystals aggregate. Journal of Solid state Chemistry. 2012;194:416-421.

11. Kubu M, Opanasenko M, Vitvarová D. Desilication of SSZ33 zeolite - Post-synthesis modification of textural and acidic properties. Catalysis Today. 2015;243:46-52.

12. Hoff TC, Gardner DW, Thilakaratne R, Proano-Aviles J, Brown RC, Tessonnier JP. Elucidating the effect of desilication on aluminum-rich ZSM-5 zeolite and its consequences on biomass catalytic fast pyrolysis. Applied Catalysis A: General. 2017;529:68-78.
13. Hasan Z, Jun JW, Kim CU, Jeong KE, Jeong SY, Jhung SH. Desilication of ZSM-5 zeolites for mesoporosity development using microwave irradiation. Materials Research Bulletin. 2014;61:469-474.

14. Ahmed MHM, Muraza O, Yoshioka M, Yokoi T. Effect of multi-step desilication and dealumination treatments on the performance of hierarchical EU-1 zeolite for converting methanol to olefins. Microporous and Mesoporous Materials. 2017;241:79-88.

15. Feng R, Yan X, Hu X, Wang Y, Li Z, Hou K, et al. Hierarchical ZSM-5 zeolite designed by combining desilication and dealumination with related study of n-heptane cracking performance. Journal of Porous Materials. 2018;25(6):17431756.

16. Tarach KA, Martinez-Triguero J, Rey F, Góra-Marek K. Hydrothermal stability and catalytic performance of desilicated highly siliceous zeolites ZSM-5. Journal of Catalysis. 2016;339:256-269.

17. Gopal S, Yoo K, Smirniotis PB. Synthesis of Al-rich ZSM-12 using TEAOH as template. Microporous and Mesoporous Materials. 2001;49(1-3):149-156

18. Sartipi S, Parashar K, Valero-Romero MJ, Santos VP, van der Linden B, Makkee M, et al. Hierarchical H-ZSM-5-supported cobalt for the direct synthesis of gasoline-range hydrocarbons from syngas: Advantages, limitations, and mechanistic insight. Journal of Catalysis. 2013;305:179-190.

19. Brunauer S, Emmett PH, Teller E. Adsorption of Gases in Multimolecular Layers. Journal of the American Chemical Society. 1938;60(2):309-319.

20. Barrett EP, Joyner LG, Halenda PP. The Determination of Pore Volume and Area Distributions in Porous Substances. I. Computations from Nitrogen Isotherms. Journal of the American Chemical Society. 1951;73(1):373-380.

21. de Boer JH, Lippens BC, Linsen BG, Broekhoff JCP, van den Heuvel A, Osinga TJ. The t-curve of multimolecular N2-adsorption. Journal of Colloid and Interface Science. 1966;21(4):405-414.

22. Martínez A, Valencia S, Murciano R, Cerqueira HS, Costa $\mathrm{AF}$, Sousa-Aguiar EF. Catalytic behavior of hybrid $\mathrm{Co} /$ $\mathrm{SiO}_{2}$-(medium-pore) zeolite catalysts during the one-stage conversion of syngas to gasoline. Applied Catalysis A: General. 2008;346(1-2):117-125.

23. Groen JC, Peffer LAA, Moulijn JA, Pérez-Ramírez J. Mesoporosity development in ZSM-5 zeolite upon optimized desilication conditions in alkaline medium. Colloids and Surfaces A: Physicochemical and Engineering Aspects. 2004;241(1-3):53-58.

24. Ernst S, Jacobs PA, Martens JA, Weitkamp J. Synthesis of zeolite ZSM-12 in the system (MTEA) ${ }_{2} \mathrm{O}-\mathrm{Na}_{2} \mathrm{O}-\mathrm{SiO}_{2}-\mathrm{Al}_{2} \mathrm{O}_{3}$ $\mathrm{H}_{2} \mathrm{O}$. Zeolites. 1987;7(5):458-462.

25. Čejka J, Košová G, Zilková N, Hrubá I. (Al)-ZSM-12: Synthesis and modification of acid sites. Studies in Surface Science and Catalysis. 2002;142:247-254. 
26. Araujo AS, Silva AOS, Souza MJB, Coutinho ACSLS, Aquino JMFB, Moura JA, et al. Crystallization of ZSM-12 Zeolite with Different Si/A1 Ratio. Adsorption. 2005;11(2):159-165.

27. Carvalho KTG, Urquieta-Gonzalez EA. Microporous-mesoporous ZSM-12 zeolites: Synthesis by using a soft template and textural, acid and catalytic properties. Catalysis Today. 2015;243:92-102.

28. Gianeto GP. Zeolitas: Características, propriedades y aplicaciones industriales. Caracas: Ediciones Innovación Tecnológica; 1990.

29. Leofanti G, Padovan M, Tozzola G, Venturelli B. Surface area and pore texture of catalysts. Catalysis Today. 1998;41(1-3):207-219.

30. Dessau RM, Valyocsik EW, Goeke NH. Aluminum zoning in ZSM-5 as revealed by selective silica removal. Zeolites. 1992;12(7):776779.

31. Groen JC, Bach T, Ziese U, Paulaime-van Donk AM, de Jong KP, Moulijn JA, et al. Creation of Hollow Zeolite Architectures by Controlled Desilication of Al-Zoned ZSM-5 Crystals. Journal of the American Chemical Society. 2005;127(31):10792-10793.
32. Groen JC, Zhu W, Brouwer S, Huynink SJ, Kapteijn F, Moulijn JA, et al. Direct Demostration of Enhanced Diffusion in Mesoporous ZSM-5 Zeolite Obtained via Controlled Desilication. Journal of the American Chemical Society. 2007;129(2):355-360.

33. Groen JC, Peffer LAA, Moulijn JA, Pérez-Ramírez J. Role of intrinsic zeolite properties on mesopore formation by desilication of MFI structures. Studies in Surface Science and Catalysis. 2005;156:401-408.

34. Bertrand-Drira C, Cheng XW, Cacciaguerra T, Trens P, Melinte G, Ersen O, et al. Mesoporous mordenites obtained by desilication: Mechanistic considerations and evaluation in catalytic oligomerization of pentene. Microporous and Mesoporous Materials. 2015;213:142-149.

35. Fathi S, Sohrabi M, Falamaki C. Improvement of H-ZSM-5 performance by alkaline treatments: Comparative catalytic study in the MTG reactions. Fuel. 2014;116:529-537. 